\title{
POPULATION AWARENESS OF THE CONSEQUENCES OF LACK OF PHYSICAL ACTIVITY
}

\author{
M. Tzankova-Kaloyanova* \\ Department "Basketball, Volleyball, Handball", Faculty of Pedagogy, National Sports Academy \\ „Vassil Levski“", Sofia, Bulgaria
}

\begin{abstract}
The era of high information and communication technologies drastically changes the lifes of Bulgarians too. Physical activity is an essential ingredient of a healthy lifestyle. Physical activities, including regular sports training and exercise, are among the most effective ways to stay in good physical and mental shape, fight overweight and obesity, and prevent their related health conditions. The purpose of this article is to analyze the level of public awareness about the health consequences due to lack of physical activity. As a result, the author has the ambition to offer ways, means and methods for prevention of socially significant diseases and their occurrences on the one hand, and on the other - to prove that by increasing physical activity, Bulgarians will improve the quality of their lives.

The text uses data from an online survey for Bulgaria, covering respondents in the active workforce age group 18-65 years. The respondents are 802 work-capable people, the survey was held in the period September-October 2019.
\end{abstract}

Key words: physical health, prevention, result

\section{INTRODUCTION}

Physical activity is one of the most important determinants of health in modern society, while sport is the fundamental element of any public policy targeting to increase physical activity. In addition, participation in sports and physical activities is related to other factors such as social interaction and inclusion.

Physical activity, health and quality of life are closely linked. The human body is designed to move and therefore needs regular physical activity to function in its optimal extent, as well as to prevent disease (1).

Immobilization leads to loss of muscle mass and muscle atrophy - the process of degenerating or becoming vestigial for muscles. As a result, the metabolism slows down and a process of fat accumulation begins.

*Correspondence to: Maria TzankovaKaloyanova, National Sports Academy ,, Vassil Levski “, Sofia, Bulgaria, Faculty of Pedagogy, Department "Basketball, Volleyball, Handball”, address: Studentski grad, Acad. Stefan Mladenov 21 str., 1700 Sofia,Bulgaria, e-mail:

maria_tzankova@abv.bg,phone: +359895029929 of physical activity is dangerous for the heart. The fat stocked in the body attacks the heart and this creates all the prerequisites for cardiovascular diseases. Exercise helps us keep blood pressure and cholesterol in normal levels. Long periods of inactivity lead to degenerative changes in the spine. Immobilization is often the cause of pain, spinal curvature, exostoses (bone spurs) in the neck and spine. A sedentary lifestyle has a detrimental effect on mental health. There is a proven correlation between lack of exercise and states of depression, low self-esteem, and gloomy thoughts.

The World Health Organization (WHO) is a key player in defining the content of antiobesity policies (2-3). According to the latest data of the WHO from March 2020, almost $62 \%$ of the population in Bulgaria is overweight - much more than the global average, which is $39 \%$. The main factors for obesity are physical activity and poor eating habits (4). When the body mass index is in the range between 18.50 to 25 - we observe normal weight. With an index of 25 to $30-$ 
overweight, and above $30 \mathrm{BMI}-$ the indices show obesity.

According to the $\mathrm{WHO}$, in Europe the share of overweight people is about $58.67 \%$, and in the European Union $-59.35 \%$. Only 5 countries are ahead of Bulgaria in the percentage of overweight people - these are the Czech Republic (62.30\%), Greece (62.30\%), Israel $(64.30 \%)$, Malta $(66.40 \%)$ and England $(63.70 \%)$.

Bulgaria is again in the top places in the rankings for obesity among population. About $13 \%$ of the people in the world have this health problem, $23.30 \%$ in Europe, and in Bulgaria their share is $25 \%$ of the population aged 18 and above (5).

The main reasons for these negative trends are found in the unhealthy ways of life. Low physical activity, increased food consumption, especially food richer in calories, lead to these unfavorable results.

\section{METHODS}

The purpose of this article is to gather information and analyze the level of awareness among the working age population about the health consequences of lack of physical activity.

To achieve our goal, we set the following tasks:

1. Development of an online survey;
2. Conducting an online survey among people in the active workforce age group;

3 . Processing of the gathered information and analysis of the achieved results;

4. Preparation of summaries and recommendations.

The object of study is the awareness of the population about the results of a lack of physical activity.

We have made a large-scale analysis of specialized literature. The main method of the study is a questionnaire. It consists of 12 questions which have single-choice responses. The survey is representative for Bulgaria. It was conducted in the period SeptemberOctober 2019. The respondents are 802 people in the working-age group (18-65 y.o.).

\section{RESULTS}

The first question is related to the lifestyle people have. Approximately 54\% think that they have a healthy way of living. $28 \%$ consider their lifestyles relatively healthy, and $18 \%$ have shared they live in unhealthy ways.

Figure 1 shows the responses to the question "How do you define your body?". We can notice that half of the respondents $-52 \%$, define their bodies as heavier than normal. $38 \%$ have defined their bodies as normal, while $10 \%$ claim they are thinner (lighterbodied) than the normal.

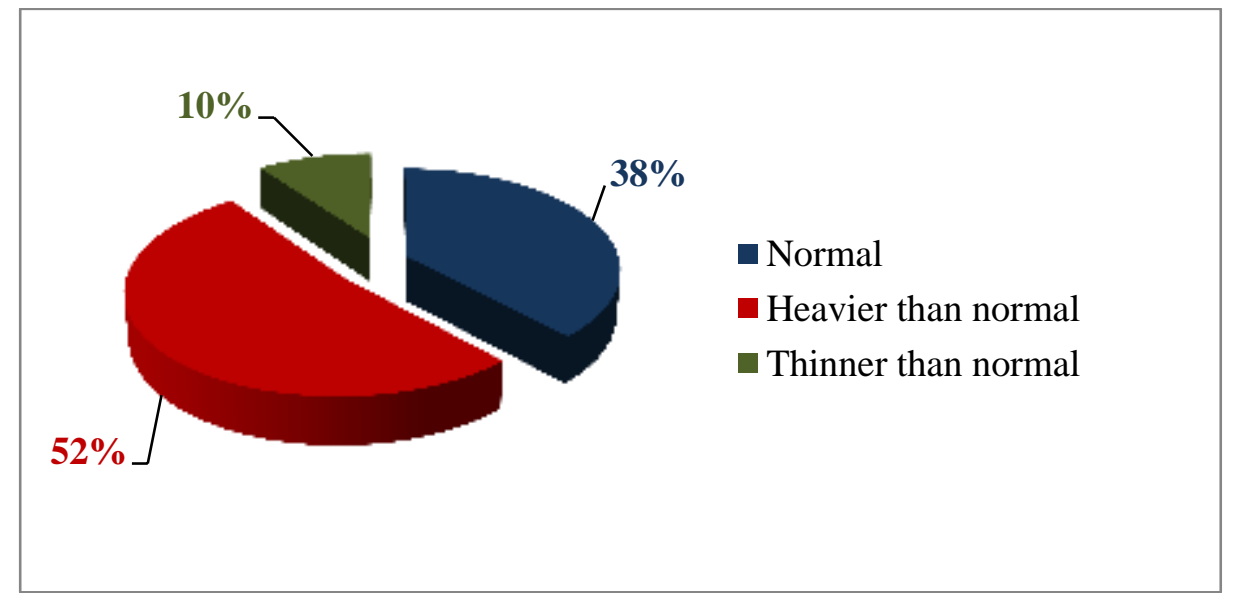

Figure 1. How do you define your body?

To the question "Do you smoke?" 58\% reply "Yes", 28\% have replied they do not smoke, and $14 \%$ have answered they smoke occasionally.

Figure 2 represents the responses to the question "Do you think that you eat healthily?"
$48 \%$ of the working-age people think their eating is healthy, $42 \%$ share that they consider their eating habits unhealthy, and every 1 in 10 persons claim they keep dietary regimen aiming to lose weight. 


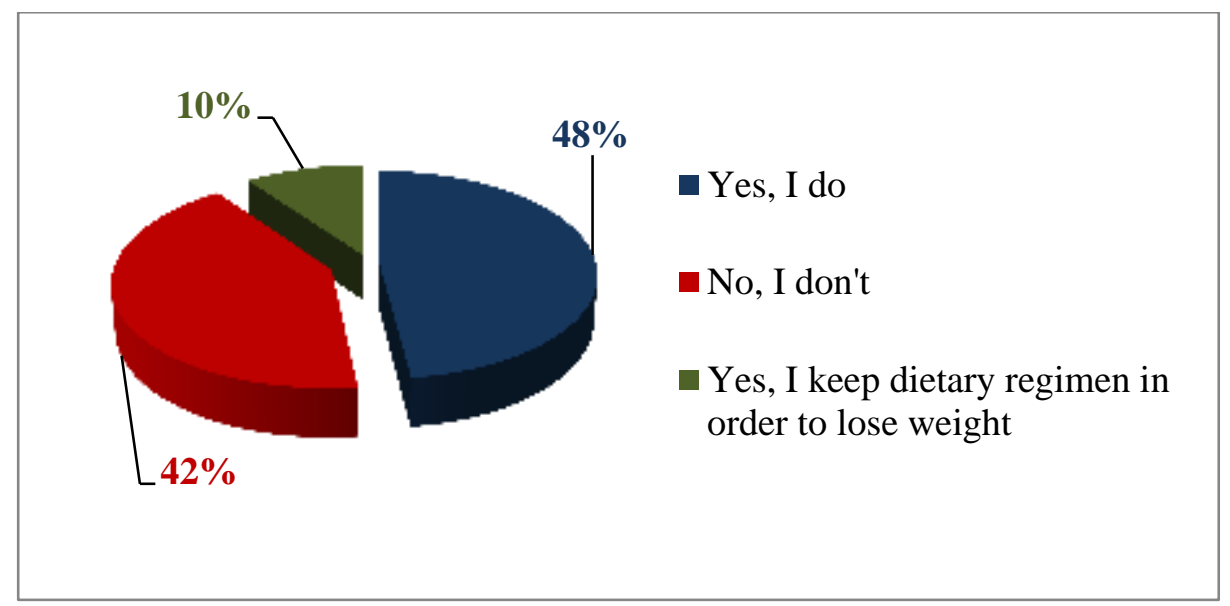

Figure 2. Do you think that you eat healthily?

To the question "Do you exercise outside of working hours?", 52\% have claimed they don't exercise, $20 \%$ have said they do, and $28 \%$ admit they rarely do physical exercise.

$70 \%$ believe that if they increase their physical activity, they will improve their quality of life. $18 \%$ don't think this is true, and $12 \%$ consider this to be true "to some extent".
$80 \%$ consider themselves informed about the benefits of sports and physical activity and their impact on the health and physical condition of a person. $8 \%$ claim they are not well-informed, while $12 \%$ think that they have partial information in Figure 3.

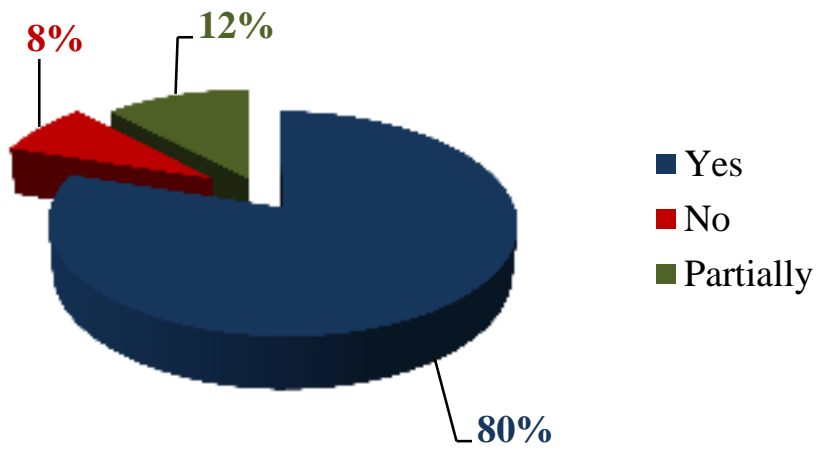

Figure 3. Are you informed about the benefits of sports and physical activity and their impact?

$77 \%$ share, that they are aware of the consequences for health from the lack of these consequences, and the remaining $12 \%$ physical activity. $11 \%$ have no knowledge of are partially aware of Figure 4.

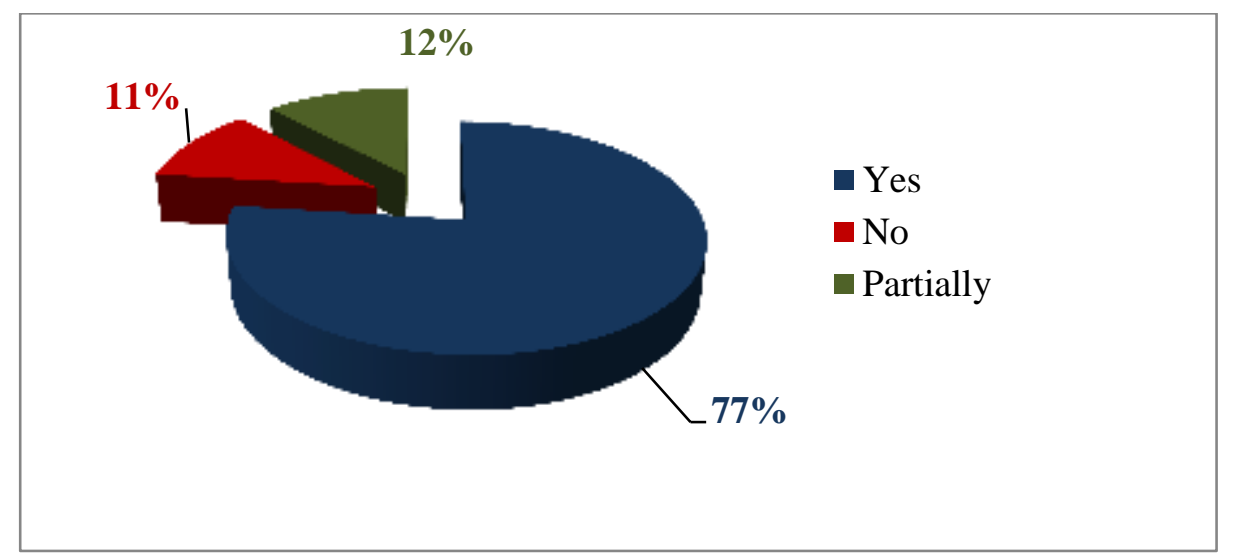

Figure 4. Are you aware of the consequences for health from the lack of physical activity? 
Considering the responses to the question "Do you think that increasing your physical activity would lead to a decrease in currently existing health issues?" almost $42 \%$ of people believe that this would be true for them. At the same time, we can see that nearly $1 / 4$ of respondents have no opinion on this claim, while $30 \%$ think that there will be no change in their health condition.

The next question is aiming to count the number of days in a week one does sports routines or exercise. $28 \%$ do once per week; over 3 times physical exercise per week do $21 \%$ of people, while $51 \%$ don't do sports at all.

Almost every second person (51\%) makes no efforts to keep in good physical shape or fitness Figure 5. 28\% rarely pay attention to their physical condition and $21 \%$ are serious about their fitness.

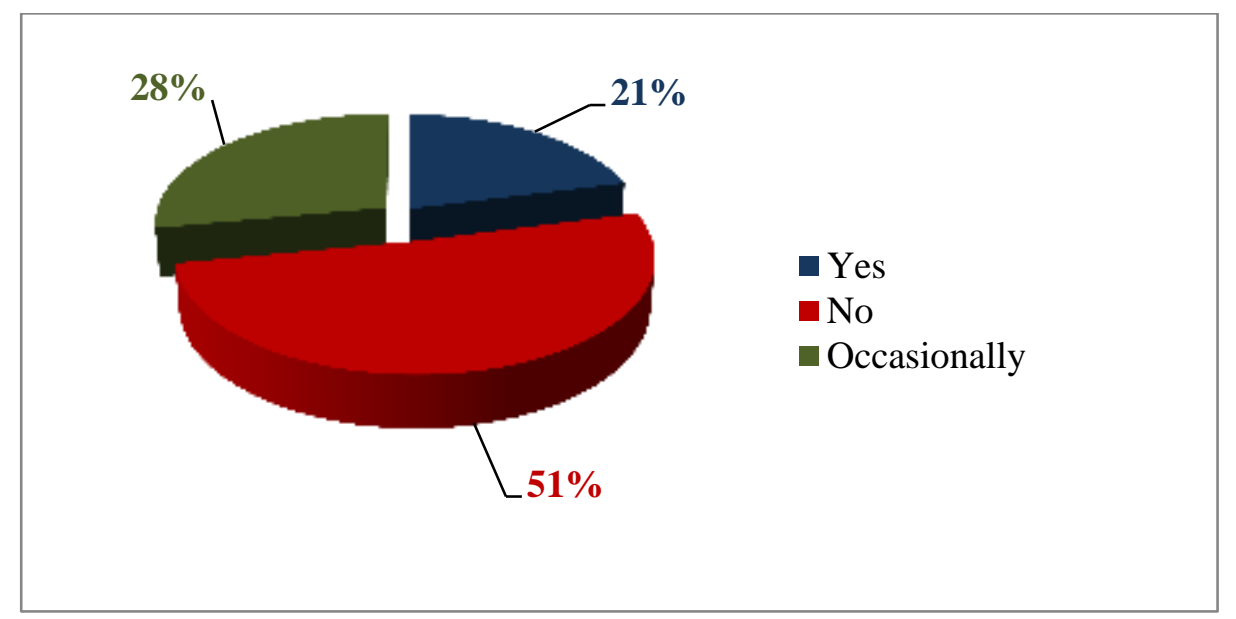

Figure 5. Do you make any efforts to keep yourself in good physical condition?

From the chart on Figure 6 we can conclude that $76 \%$ of the respondents agree with the claim that increasing physical activity would improve the quality of life. Those who don't agree with this are $9 \%$ of all in the workingage group, and the rest $15 \%$ have answered with "maybe" to this statement.

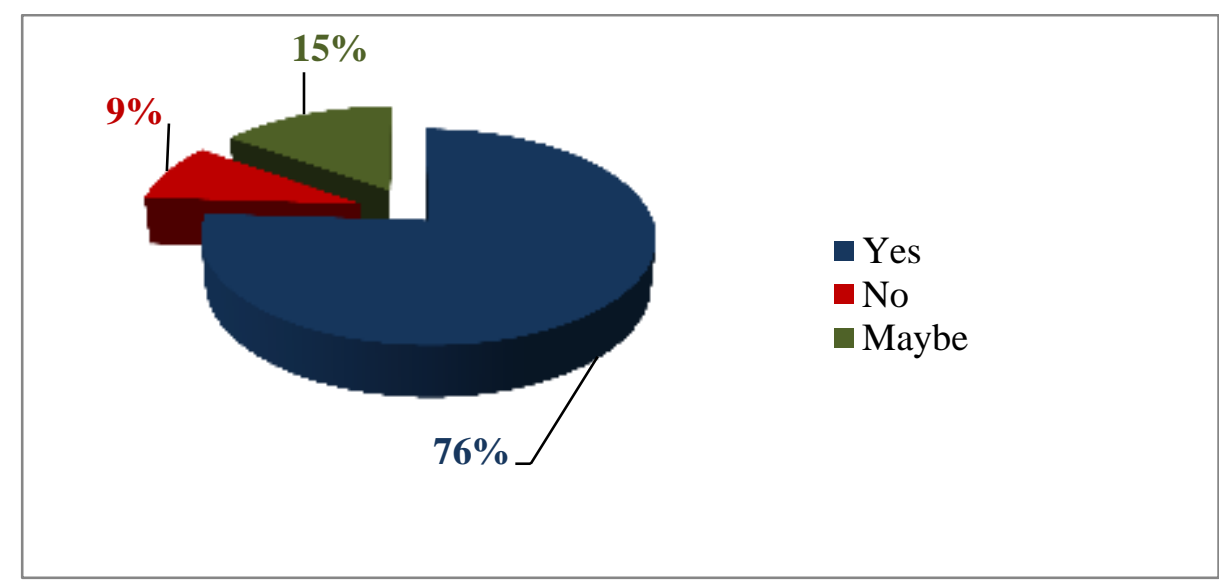

Figure 6. Do you agree with the statement that increasing physical activity would improve the quality of life?

\section{CONCLUSIONS}

Based on the analysis of the processed results, we can summarize that the attitude of active working-age Bulgarian citizens to physical activity as a basis for a healthy lifestyle is positive.
It should be noted that despite the lack of sports habits among a major part of Bulgarians, their self-esteem is high in terms of leading a healthy lifestyle.

We have identified the need for information / educational campaign, focusing on the health benefits which physical activity brings. 
Regular exercise will lead to an increase in high-density lipoprotein (HDL) or the socalled "good cholesterol", and will help reduce unhealthy triglycerides, which will lead to reduced risk of cardiovascular diseases.

Balancing the food that we eat is very important for a healthy lifestyle. This requires control and discipline towards the food, its quantity, type and its nutritional values.

Physical activities in combination with healthy eating habits are among the most important fundaments, and the most reliable means for decreasing the risk of diseases.

In order to be more physically active, we need to accumulate physical activity throughout the week. This means physical exercise minimum 1 hour per day or 150 minutes weekly.

People who have more sedentary lifestyles have to start with short time-slots of light physical activities, which would be gradually extended - in terms of intensity, time duration, and frequency. People in older age groups, as well as those with clearly defined and diagnosed illnesses or health conditions, plus the ones who live sedentary lives, must learn about the beneficial impact of physical exercise, and should become more active.

\section{REFERENCES}

1. EU Guidelines for Physical Activity. Recommended political actions supporting physical activity for health promotion. Brussels, October 10, p.3, 2008

2. Resolution WHA53.17 on Prevention and control of non-communicable diseases. Geneva, World Health Organization, 2000.

3. National Health Strategy 2014-2020.

4. BNR, 2019 Download URL: https://www.bnr.bg/hristobotev/post/10123 6051

5. World Health, 2019 http://www.euro.who.int/obesity 